\title{
Investigation of the electrochemical behaviour of TiMo alloys in simulated physiological solutions
}

\author{
G. Bolat ${ }^{\mathrm{a}}$, D. Marecia ${ }^{\mathrm{a}}$ R. Chelariu ${ }^{\mathrm{b}}$, J. Izquierdoc , S. González ${ }^{\mathrm{c}}$, R.M. Souto ${ }^{\mathrm{c}, \mathrm{d}}$ \\ a “Gheorghe Asachi” Technical University of Iasi, Faculty of Chemical Engineering and Environmental \\ Protection, 73 Prof. dr. doc. D. Mangeron St., 700050, Iasi, Romania \\ b “Gheorghe Asachi” Technical University of Iasi, Faculty of Materials Science and Engineering, 41 \\ Prof. dr. doc. D. Mangeron St., 700050, Iasi, Romania \\ c University of La Laguna, Department of Physical Chemistry, E-38205 La Laguna (Tenerife, Canary \\ Islands), Spain \\ d University of La Laguna, Instituto Universitario de Materiales y Nanotecnologías, E-38200 La Laguna \\ (Tenerife, Canary Islands), Spain
}

\begin{abstract}
.
This paper addresses on the electrochemical behaviour of three TiMo alloys exposed to simulated physiological environments. Their stability and corrosion resistance was characterized in order to explore the potential application for the manufacturing of implant materials. Ringer's solution together with an acidic modification of the Ringer's solution $(\mathrm{pH}=3.1)$ at room temperature were considered. Both electrochemical methods (namely, potentiodynamic polarization curves and electrochemical impedance spectroscopy, EIS), and spatially-resolved scanning electrochemical microscopy (SECM), were used. Additionally, surface characterization was made employing optical microscopy and scanning electron microscopy (SEM). The oxide films formed on the TiMo alloys in neutral and acidic Ringer's solutions effectively protect the metal from dissolution in this environment, and no breakdown of the passive layer occurs in the potential range up to $+1.00 \mathrm{~V}$ vs. SCE. SEM micrographs of retrieved samples do not show corrosion pits, cracks, or any other defects despite the rather high positive potential values reached during the potential excursion. EIS data reveal that two-layer oxide films are formed, consisting of a porous outer layer and a compact inner layer (approximately 5-6 nm thick), the latter accounting almost completely for the corrosion resistance of the materials. The corrosion resistance of the inner compact film towards metal dissolution is smaller in the acidic environment, whereas it increases with higher Mo contents in the alloy. The passive oxide films exhibit dielectric characteristics towards charge transfer, and they are imaged as insulators by scanning electrochemical microscopy.
\end{abstract}

Keywords: TiMo alloys, corrosion resistance, passivity, Ringer’s solution, EIS, SECM. 


\section{Introduction}

Titanium-based materials posess a combination of properties that make them adequate for biomedical structural application as orthopaedic and dental implants [1-5]. The low elastic modulus, high strength, and the affinity and reactivity in contact with oxygen or aqueous solutions, which lead to form a compact and strong adherent oxide layer on their surface, all of these result in a good biological and mechanical compatibility. Although titanium-based materials are among the most corrosionresistant materials in human body fluids, and they have been extensively employed in implantology, there still remains some concern in the scientific literature regarding their use because of the observation of corrosion processes in retrieved prosthesis, as well as reports on the occurrence of metallosis [6]. Metal ion release into peri-prosthetic tissues has been found from bone fixation implants [7], and in serum in ionic states [8] and bound to proteins [9]. More interestingly, distributed metal has been recently found in inflamed tissues adjacent to commercially pure titanium skin-penetrating devices despite the absence of wear or loads [10]. In the latter, release of titanium into the body could only be attributed to either micro-motion [10] or localized corrosion [11,12]. To diminish the impact of these limitations, a main research trend is the development of $\beta$-type (body-centered cubic) titanium alloys with biomechanical compatibility, low modulus and biochemical compatibility due to their greater corrosion resistance $[13,14]$. The stability of the $\beta$-phase in the case of titanium alloys is expressed as the sum of the weighted averages of the alloying elements in wt.\% known as the Mo equivalent $[15,16]$. A value of Mo equivalent in the range 8-24 wt.\% relates to $\beta$-metastable titanium alloys because the contents of $\beta$-stabilizers is high enough to prevent any martensitic transformation in the $\beta$ phase from quenching to room temperature $[15,16]$.

Molybdenum is used as alloying element for titanium because it has good thermodynamic stability [17,18]. Molybdenum is considered to be instrumental in regulating the $\mathrm{pH}$ balance in the body, and acts as a cofactor for a certain number of enzymes in humans [19,20]. The biocompatibility and corrosion resistance of TiMo alloys has already been established in the scientific literature [21-23]. It is considered that the addition of Mo to pure $\mathrm{Ti}$, up to 15 wt.\% content, improves the protection characteristics of the oxide films spontaneously formed on the materials oxides. Therefore, the Ti15Mo (\% wt.) alloy has been recently accepted for the manufacture of devices for implantation in humans, with composition allowances fixed under norm ASTM F 2066 [24]. Nevertheless, we have recently observed that Ti20Mo alloy possess better corrosion resistance than commercially pure Ti when exposed 
to artificial saliva [25]. Therefore, it was thought that Mo contents greater than $15 \%$ wt. might lead to the production of TiMo alloys with even better corrosion resistance for implant application.

The present communication concerns a report on in vitro electrochemical characterizations of three TiMo alloys exposed to simulated physiological environments as to investigate their chemical activity and corrosion resistance. Two alloys with Mo contents just below and above the composition given by the ASTM F 2066 norm were considered (namely Ti12Mo and Ti20Mo), in order to investigate the eventual occurrence of a deleterious effect on the corrosion resistance of the materials due to the higher Mo content. Additionally, a TiMo alloy with significantly higher Mo addition (Ti40Mo) was also explored. The work was carried out using Ringer's solution together with an acidic modification of the Ringer's solution $(\mathrm{pH}=3.1)$ at room temperature. Both conventional and localized electrochemical techniques have been employed, including DC potentiodynamic polarization methods (PPM), electrochemical impedance spectroscopy (EIS), and scanning electrochemical microscopy (SECM).

\section{Materials and methods}

\subsection{Materials}

Experiments were carried out on three TiMo alloys with different composition (12, 20 and 40 wt.\% of Mo) that have been synthesized by cold crucible levitation melting in an induction furnace (Fives Celes, Lautenbach, France), following the procedure described before [26]. The samples in the form of rods were cut into disks of $0.28 \mathrm{~cm}^{2}$ circular area, they were ground with $\mathrm{SiC}$ abrasive paper up to 2000 grit, followed by a final polishing stage using $1 \mu \mathrm{m}$ alumina suspension. In the case of the samples investigated using scanning electrochemical microscopy, an additional polishing stage using 0.3 $\mu \mathrm{m}$ alumina suspension was employed in order to further diminish the surface roughening that samples could be imaged at a shorter distance for greater spatial resolution. The samples were degreased with ethyl alcohol, ultrasonically cleaned in deionized water, and finally dried under air stream.

Specimens were embedded in a polytetrafluoroethylene (PTFE) holder specifically designed to facilitate connection to a rotating disc electrode holder (model EDI 101T, Radiometer Analytical). A polymeric resin was used to ensure a tight seal between the specimen and the PTFE holder, in order to 
avoid the occurrence of crevice corrosion [27]. The exposed surface of the materials to the test environments were discs of $0.28 \mathrm{~cm}^{2}$ area.

\subsection{Electrochemical measurements}

The tests were conducted in two artificial physiological solutions based on the Ringer's solution. All components were of analytical grade, and Milli-Q deionised water. Ringer's solution was made from $\mathrm{NaCl}$ : $8.6 \mathrm{~g} / \mathrm{L} \mathrm{NaCl}, 0.3 \mathrm{~g} / \mathrm{L} \mathrm{KCl}$, and $0.48 \mathrm{~g} / \mathrm{L} \mathrm{CaCl}$. The $\mathrm{pH}$ of Ringer's solution was 6.9 in the naturally aerated solution. An acidified version of Ringer's solutions was also made by adding $\mathrm{HCl}$ to Ringer's solution to bring the $\mathrm{pH}$ down to 3.1. This addition caused only a small change in the concentrations of the other components. The acidic $\mathrm{pH}$ was chosen because the tissue adjacent to an implant under distress is considered to become acidic [28]. Measurements were performed at room temperature $\left(22 \pm 3{ }^{\circ} \mathrm{C}\right)$.

Conventional electrochemical measurements on the TiMo alloys were conducted employing a three-electrode configuration. The specimens were taken as the working electrode. They were placed in a glass corrosion cell, which was filled with the artificial physiological solution. A saturated calomel electrode (SCE) was used as the reference electrode, and a platinum coil as the counter electrode. Electrochemical techniques were performed using a PARSTAT 4000 potentiostat supplied by Princeton Applied Research (PAR, Princeton, NJ, USA). The instrument was controlled by a personal computer and specific software (VersaStudio, PAR, USA). The samples were immersed into the artificial physiological solution for an hour in order to attain their spontaneous open circuit potential values $\left(E_{o c p}\right)$. Electrochemical impedance spectra (EIS) were carried out in the frequency range of $100 \mathrm{kHz}$ down to $1 \mathrm{mHz}$ by applying an alternating sinusoidal potential with an amplitude of $10 \mathrm{mV}$. EIS spectra were first recorded at their open circuit potential values, and subsequently the potential of the sample was set at $+0.40 \mathrm{~V}$ vs. SCE for $30 \mathrm{~min}$ before recording the EIS data of the polarized sample. This potential value was chosen to be more positive than any reported to be achieved in the human body for Ti implants [29]. The EIS experimental data were fitted and analyzed in terms of equivalent circuits (EC) using a non-linear least squares fit method (ZSimpWin 2.00 software [30]) to obtain the relevant impedance parameters. Potentiodynamic measurements were also carried out in the artificial physiological solutions. These measurements were conducted by stepping the potential from -0.80 to $+1.00 \mathrm{~V}$ vs. SCE using a scanning rate of $0.5 \mathrm{mV} \mathrm{s}^{-1}$. Before recording the potentiodynamic polarization curves, the TiMo samples were left unpolarized into the test solution for 1 hour. The electrochemical 
tests were repeated three times for each TiMo specimen using a freshly polished surface as described before.

A SECM equipment supplied by Sensolytics (Bochum, Germany), was employed for spatiallyresolved characterization of the electrochemical reactivity of the TiMo alloys. The instrument was built around a PalmSens (Utrecht, The Netherlands) electrochemical interface, all controlled with a personal computer. The alloy specimens were either tested at their open circuit potentials in the test solutions, or polarized using the bipotentiostat in the electrochemical interface. The specimens were mounted horizontally facing upwards at the bottom of a cell made of polytetrafluoroethene, which was equipped with an $\mathrm{Ag} / \mathrm{AgCl} / 3 \mathrm{M} \mathrm{KCl}$ reference electrode and a platinum counter electrode. For the sake of consistency, potentials were expressed in relation to the standard calomel electrode by taking in account the potential difference between the two reference electrodes. The electrochemical cell was located inside a Faraday cage. Temperature control was not performed in the SECM, and data were recorded at ambient temperature. Tip microelectrodes were made from $10 \mu \mathrm{m}$ dia. platinum wires sealed in glass. $0.5 \mathrm{mM}$ ferrocene-methanol was added to the artificial physiological solution to act as electrochemical mediator at the tip. The tip was kept at a constant potential of $+0.46 \mathrm{~V}$ vs. SCE to ensure the diffusionlimited oxidation of ferrocene-methanol [31]. The establishment of the operating tip distance over the sample was performed by slowly approaching the surface of the TiMo alloy sample with the tip, and simultaneously recording the measured current at the microelectrode vs. $z$ displacement (i.e., $z$-approach curve), until the measured current was equal to $30 \%$ of the steady-state value in the bulk of the electrolyte. Subsequently, the tip was withdrawn $10 \mu \mathrm{m}$ from the sample surface, and SECM images were obtained with a scan rate of $30 \mu \mathrm{m} \mathrm{s}^{-1}$ by scanning the tip at constant height over an arbitrary area of $250 \mu \mathrm{m}$ x $250 \mu \mathrm{m}$ of the exposed alloy. For the sake of normalization, SECM data are presented as dimensionless tip currents, $i / i t, \infty$, where $(i)$ is the feedback current measured at the tip while scanning the substrate, and $i_{T, \infty}$ is the limiting current determined when the tip is far from the surface. Values greater than one are obtained when the redox mediator is regenerated on the electrochemically-active substrate (positive feedback behaviour), whereas an insulating substrate hinders the diffusion the redox species leading to values smaller than one (negative feedback behaviour). SECM imaging was first performed while the samples were still at their corresponding ocp. Next, imaging was performed on the polarized samples, starting at the $-0.54 \mathrm{~V}$ vs. SCE, and subsequently stepped to more positive potentials. for imaging 


\subsection{Surface analysis}

The structural characterization of the as-received TiMo alloys was performed by optical microscopy. An inverted metallographic microscope (XJP-6A, Chongqing Optical \& Electrical Instrument Co., Ltd., Chongqing, China) controlled using dedicated software (Materials Plus). The samples were mechanically polished to a final level of $0.02 \mu \mathrm{m}$ alumina suspension and subsequently etched in a solution of water, hydrofluoric acid, and nitric acid [32].

After the electrochemical measurements, specimens were retrieved from the test solutions to qualitatively characterize their topography by scanning electron microscopy (SEM, Quanta 3D Model AL99/D8229, FEI, Hillsboro, OR, USA) operating with beam energy $20 \mathrm{kV}$.

\section{Results and discussion}

\subsection{Microstructure}

The microstructures of the samples are shown in Figure 1. They mainly consist of an acicular microstructure with small non oriented grains, and this structure is more noticeable the higher the molybdenum content in the alloy. The increase of Mo content led to a different morphology of the primary $\beta$-phase dendrites because the values of the thermo-physical properties and the melting temperatures of these alloys strongly depend on their chemical composition. Preferential growth of primary $\beta$-phase dendrites with smaller sizes is observed with increasing Mo content in the alloys.

\subsection{Potentiodynamic polarization and immersion}

Open circuit potential $\left(E_{o c p}\right)$ values of the three TiMo alloys in conventional and acidic Ringer's solutions at room temperature after 1 hour immersion are listed in Table 1. From the observation of the values recorded for each material in the two solutions, it can be deduced that the Ti40Mo alloy exhibited the most positive values, while the Ti12Mo alloy showed the most negative ones. The more aggressive character of the acidic solution towards corrosive attack is evidenced by the systematic shift of the open circuit potential values of the alloys in the negative direction, which evidences that the spontaneously developed oxide films on the samples are less protective when exposed to a lower $\mathrm{pH}$. It is well known that the corrosion resistance of a given material depends on several factors such as composition, environment and microstructure [33]. Since the three TiMo alloys exhibit a common basic 
microstructure, it can be deduced that the addition of Mo to Ti leads to the improvement of the protection characteristics of the passive oxide layers formed in the two environments.

The potentiodynamic polarization curves of the samples in the two artificial physiological solutions are displayed in Figure 2. This provides basic information on corrosion for subsequent comparison. The samples were polarized from $-0.80 \mathrm{~V}$ vs. SCE; at this potential the cathodic branches of the different alloys immersed in Ringer's solution to overlap in the graphs due to the common charge transfer control for the oxygen reduction reaction. Though not as effectively as in the previous case due to slightly different rates for the same reduction reaction of hydrogen ions, the cathodic branches of the curves measured in the acidic solution are also sufficiently close to regard the potential value $-0.80 \mathrm{~V}$ vs. SCE as the starting point for the potentiodynamic polarization experiments. On the other hand, the anodic limit potential (i.e., +1.00 V vs. SCE) was chosen significantly higher than polarization values ever measured in the human body [29]. The shape of the anodic branches revealed the onset of passivity for the alloys in both solutions, which is evidenced by the observation of an active-passive transition in all the curves at potentials slightly more positive than their corresponding corrosion potential values $\left(E_{c o r}\right)$. Tafel analysis of both the anodic and cathodic branches of the polarization plots delivered values for $E_{c o r}$ and corrosion current densities $\left(j_{c o r}\right)$. Table 2 gives the average values determined for these parameters. In all cases the values determined for $E_{\text {cor }}$ are smaller than those corresponding to open circuit potential (cf. Table 1). This behaviour arises from the reduction of the oxide layer spontaneously formed on the surface of the alloys upon immersion in the solution that occurs during application of a cathodic polarization at $-0.80 \mathrm{~V}$ vs. SCE. Such oxide layer was evidenced by the shift of the open circuit potential of the samples towards more positive potentials upon immersion in the test solutions (cf. Figure 3). Yet, the variation in the $E_{c o r}$ values with alloy composition determined from polarization measurements agree well with those described before for the open circuit potential $\left(E_{\text {ocp }}\right)$ values in the two environments. According to Blackwood et al. [34], the shift of to positive values shows an increase of the passive film thickness and correspondingly, a decrease of the corrosion rate. Further excursion of the potential in the positive direction results in the measurement of a constant current density for each material when immersed in Ringer's solution until reaching the limiting anodic potential value. The oxide films formed on the TiMo alloys in Ringer's solution effectively protect the metal from dissolution in this environment, and no breakdown of the passive layer occurs in all the potential range under consideration. A somewhat different situation is found from inspection of the potentiodynamic polarization curves measured in the acidic Ringer’s solution. In this case, the passive current densities 
are not kept constant for the duration of the experiments, but they show a trend to increase with the excursion of potential for $E>+0.20 \mathrm{~V}$ vs. SCE, which indicates than some metal dissolution may occur through the oxide film in the more aggressive environment. Yet, no indications of localized breakdown of the passive film in the acidic solution are observed in these curves, which would have appeared as an abrupt increase of the current in the $E$-log $j$ plots. Values for the passive current densities for each material in the two test solutions are also provided in Table 2.

The stability of the oxide films formed on the TiMo alloys after potentiodynamic polarization up to $+1.00 \mathrm{~V}$ vs. SCE in both artificial physiological solutions was confirmed using scanning electron microscopy. Typical SEM micrographs of the retrieved TiMo specimens are shown in Figure 4. They revealed that uniform surfaces occurred on all TiMo alloys, and no signs of features other than the scratches due to polishing during preparation of the surfaces could be observed. That is, no corrosion pits, cracks, or any other defects were formed despite the rather high positive potential values reached during the potential excursion in the aggressive acidic Ringer's solution, thus supporting the observations from electrochemical experiments. This observation is important because other titaniumbased materials, such as nitinol [5,35] and TiZr alloys [36], experience pitting corrosion under these conditions.

\subsection{Electrochemical impedance spectroscopy}

Impedance spectra of Ti12Mo, Ti20Mo and Ti40Mo alloy in the two electrolytes at the Eocp were presented as Bode-phase and Bode-magnitude plots in Figure 4. It is observed that these alloys present similar spectra in conventional and acidic Ringer's solutions, and they correspond to systems exhibiting two time constants as revealed by the presence of two maxima in the Bode-phase diagrams. That is, they can be divided into two distinct frequency ranges: the time constant in the high-frequency part, which arises from the uncompensated ohmic resistance due to the electrolytic solution and the impedance characteristics resulting from the penetration of the electrolyte through a porous film, and the lowfrequency part accounting for the processes taking place at the substrate/electrolyte interface. This agrees with the general understanding that passive films formed on most metals [37], including titanium and its alloys [38,39], consist of two layers, a thin compact oxide in direct contact with the base unoxidized metal, and the outer thicker and more porous layer that is in direct contact with the environment. The thicknesses of the two layers are quite different and depend on the nature of the metal substrate and the environment. They typically amount a few nanometers in the case of the inner layer, 
whereas the outer layers may extend to some micrometers in certain cases. High impedance values (in the order of $10^{6} \Omega \mathrm{cm}^{2}$ ) were determined in the low-frequency region, indicating high corrosion resistance in both Ringer's solutions at the substrate/electrolyte interface, typical of a compact inner oxide layer with barrier characteristics towards the passage of current through it.

The presence of these two time constants can be described by means of an equivalent circuit (EC) with two RC components as shown in Figure 5. This has been proposed to give the electrical representation of two-layer surface films consisting of a barrier-type compact inner layer and a relatively porous outer layer formed on titanium [38,39] and titanium-rich alloys, such as Ti6Al4V [40-42], Ti6Al7Nb [41,43,44], Ti13Nb13Zr [41], and Ti-29Nb-13Ta-4.6Zr [45]. It has also been found applicable to alloys with lower Ti contents including Ti35Nb [46], TiNbSn [47], TiNbHf [48] alloys, nitinol [49], and even to ZrTi alloys [36,50]. The following elements are considered: a solution resistance $R_{\text {sol }}$ of the test electrolyte, electrical leads, etc., the additional resistance $R_{1}$ of the solution inside the pores, the capacitance of the pore wall $C_{1}$, and the resistance and the capacitance of the inner barrier layer $\left(R_{2}, C_{2}\right)$. Constant phase elements $(\mathrm{CPE}, Q)$ were used in the EC instead of capacitors, allowing for the effects of deviations to ideality related to electrode roughness and heterogeneities of the surface films to be considered. In fact, the impedance of a CPE is defined as:

$$
Z_{(C P E)}=\frac{1}{Y_{0}(j \omega)^{n}}
$$

where $\omega$ is the angular frequency and $Y_{0}$ is a constant, and the value of the exponent $n$, ranging $-1 \leq n \leq$ 1 , indicates the deviation from ideal capacitive behaviour (e.g., when $n \approx 1$ ). The impedance results were obtained with the ZSimpWin software and the quality of the fits was evaluated by their Chi-squared values. A very good correlation was obtained between EIS data using the proposed equivalent circuit and the experimental impedance spectra, as it is evidenced by the solid lines corresponding to the fitted spectra passing through the measured data (discrete points) in Figure 4. The values of fitted parameters of the EC are listed in Table 3. High values of $R_{2}$ (in the order of $10^{6} \Omega \mathrm{cm}^{2}$ ) are determined at their open circuit potential values for the three TiMo alloys in both simulated physiological solutions, confirming the formation of an inner compact layer with high corrosion protection ability for all the systems. It can be observed that the variation in the values for $R_{2}$ with the nature of the alloy and the aggressivity of the electrolyte closely matches both the trend and the magnitude of change in the values of jcor determined from the polarization curves given in Table 2, thus supporting the consistency of the electrochemical data obtained using two different techniques. 
From the fitted values of Table 3 some differences are evident between the characteristics of the oxide films in both solutions. In fact, $R_{2}$ values are always smaller in the acidic electrolyte for each alloy, thus indicating that the inner film is less protective in this environment. The opposite trend is found in the impedance parameter related to the constant phase elements $Q_{2}$, which can be related to the thickness of this inner layer. Though exponent values $n$ smaller than 1 were always found, yet the values were greater than 0.8 , thus $Q$ values can be considered to represent a non-ideal capacitor. Then, capacitance values for both the compact oxide layer and the electrolyte/oxide interfaces could be extracted from the CPE parameters using [51]:

$$
C=\left(R^{1-n} Q\right)^{1 / n}
$$

In this way, the order of magnitude of the capacitance values determined for both $C_{2}$ and $C_{1}$ were found to correspond to those typical for a compact barrier layer and for a porous film interface at which charge transfer occurs, respectively.

Assuming that the capacitance may be related to the thickness as $C=\varepsilon \varepsilon 0 A / d$, where $\varepsilon$ is the dielectric constant of the oxide, $\varepsilon 0$ the vacuum permittivity, $A$ the geometric area, and $d$ is the thickness. Higher values of capacitance correspond to smaller thicknesses. To that end, the Ti/Mo ratio in the metal matrix was assumed to hold also in the oxide layer, using $\varepsilon=114$ for $\mathrm{TiO}_{2}$ [52,53] and $\varepsilon=16$ for $\mathrm{MoO}_{3}$ [54], and the surface roughness factor as unity. The thicknesses of the inner oxide films formed on the different materials are given in Table 4. It is found that the thickness of the inner compact layer remains almost invariant for a given TiMo alloy with the change in $\mathrm{pH}$ of the Ringer's solution, though the resistance of this layer towards metal dissolution is smaller in the acidic environment as given by the smaller $R_{2}$ values obtained in this case. This observation is also supported by the significantly higher values of $j_{\text {pas }}$ determined from the potentiodynamic polarization curves measured in the acidic solution (cf. Table 2). Next, the thickness of the inner compact layer is significantly smaller for Ti40 alloy compared to the other two alloys (namely ca. 25\% reduction compared to Ti20Mo). A more compact inner oxide layer must be formed on this alloy in order to account for its higher resistance given in Table 3.

EIS measurements were also performed on TiMo alloy samples polarized at $+0.40 \mathrm{~V}$ vs. SCE in both simulated physiological solutions, and the corresponding spectra are given in Figure 6. Again the Bode-phase plots correspond to a physicochemical system characterized by two time constants. The chisquare value $\left(\chi^{2}\right)$ between $5 \times 10^{-4}$ and $10^{-5}$ points to excellent agreement between the experimental data and simulated values. The values of fitted parameters of the EC are listed in Table 5. Higher polarization 
resistance values in the low frequency range of the Bode-modulus plots are observed in all cases compared to the spectra measured at their Eocp, which demonstrates that after polarization of the samples at $+0.40 \mathrm{~V}$ vs. SCE, the passive layer formed on the surface of the TiMo alloys in Ringer's solution is either more compact or more homogeneous than that formed in acidic Ringer's solution. This happens though a slightly thinner passive film is produced in the acidic environment as indicated by the thickness values given in Table 4 .

\subsection{Scanning electrochemical microscopy}

Since the electrochemical studies described in the previous two Sections provide electrochemical information that is averaged over the exposed area of the material, scanning electrochemical microscopy (SECM) was employed to detect local changes in the chemical reactivity of the passive layers formed on the alloys [31,55,56].

Figures 7-9 depict the SECM images measured for the TiMo alloys immersed in the two artificial physiological solutions while they were subjected to different electrical conditions. Normalized tip currents greater than 1 were usually obtained when the alloys were polarized at $-0.54 \mathrm{~V}$ vs. SCE (cf. images (B) in figs. 7-9). Yet some variations can be observed depending on the nature of the alloys and the composition of the test solution. The biggest normalized tip currents were found for Ti40Mo, followed by Ti20Mo, whereas the smallest were found for Ti12Mo, and they were smaller than one for the latter (see Figure 7B-left). That is, the surface of this alloy does not facilitate the regeneration of ferrocene-methanol despite the negative potential applied to the sample. This variation in the electrochemical activity of the cathodically-polarized alloys in Ringer's solution closely matches the variation in their open circuit potentials as listed in Table 1, the nobler value exhibited by Ti40Mo, and the more active for Ti12Mo. That is, polarization of the sample at $-0.54 \mathrm{~V}$ vs. SCE corresponds to a greater cathodic overvoltage for the alloys with higher Mo contents, which exhibit the more positive ocp values. Therefore, only partial reduction of the oxide film has occurred for the Ti12Mo sample at this cathodic potential. These observations are thus in good agreement with the spontaneous formation of an insulating oxide film on the alloys upon immersion in a Ringer’s physiological solution.

On the other hand, increased normalized tip currents were always observed in acidic Ringer's solution, supporting that the oxide films spontaneously formed on the surface of the alloys at their ocp are more easily reduced at this potential when immersed in the more acidic environment. Yet no evidence of a heterogeneous activation of the alloy surfaces can be found in the images, which show a 
rather featureless surface apart from the systematic variations in a random direction that arise from the tilted surfaces. More stable passive films are formed at the ocp when the alloys are immersed in neutral Ringer's solution, and polarization at $-0.54 \mathrm{~V}$ vs. SCE. The reduction of the spontaneously-formed passive oxide film appears to be more difficult when the alloys are exposed in the neutral Ringer's solution.

An insulating surface towards regeneration of ferrocene-methanol was found when the alloys were polarized anodically as deduced from the inspection of images (C) in figs. 7-9. Normalized tip currents smaller than one were measured in both physiological solutions for the three alloys while polarized at $+0.16 \mathrm{~V}$ vs. SCE. No clear differences between the insulating characteristics of the passive films formed on each alloys could be distinguished at this time from the SECM maps obtained for each alloy in the tested environments. This observation agrees with the results from EIS data that indicated that the passive layers formed under anodic polarization on the three alloys and in both Ringer's solution and acidic Ringer’s solution exhibit similar thicknesses and resistivities.

A more complex situation is observed from the inspection of the SECM images recorded at open circuit potential for each alloy. In this case, the dynamic process of oxide film formation could be followed through the maps labelled (A) in figs. 7-9 in some cases. This was possible because imaging of the surface was initiated shortly after immersion of the specimens in the electrolyte, that is, without waiting until a stable open circuit potential reading was attained. In this way, passivation of the surface was progressively advancing during the scanning movement of the SECM probe for image recording. Earlier times correspond to the location indicated by the axes origin in the figures, and tip movement advanced from left to right in consecutive lines, and from the front to the back in the plots. It can be observed that oxide film formation, that is related to the surface becoming an insulator for ferrocenemethanol regeneration, does not progress in a homogeneous manner, neither at the same rate in every system. Both local microcathodes and microanodes must be distributed on the surface during oxide film formation, because an oxidant species from the electrolyte must consume the electrons left in the metal during its oxidation. This action is performed by dissolved oxygen molecules in the electrolyte in Ringer's solution, whereas hydrogen ions are reduced in the acidic electrolyte. A more active surface is imaged at earlier exposures in the case of the Ti40Mo alloy immersed in the acidic electrolyte, and the transition from positive to negative feedback behaviours occurs at longer exposures. Normalized currents greater than one are observed all over the surface, indicating the Ti40Mo alloy is not yet covered by a protective passive oxide layer at short exposures in the acidic environment (see Figure 9A- 
right). On the contrary, negative feedback effects are observed for the other two alloys in this environment even at the beginning of the experiment, and further growth of the oxide film occurs with the elapse of time as evidenced by the continuous decrease of the values of the normalized currents as the tip continues rastering the surface (cf. Figure 7A-right). The described trend in the insulating characteristics of the passive films spontaneously formed on the TiMo alloys at the ocp when exposed to acidic Ringer's solution is precisely the opposite to what it happens in the neutral solution. That is, a highly electrically-insulating passive film is formed on Ti40Mo in Ringer's solution characterized by normalized currents averaging 0.25 (Figure 9A-left). The dynamics of passive film formation is still evident at this early exposures, as indicated by the spikes that correspond to local sites in the surface of the passivating metal where the oxide film is still thinner. Average higher currents are measured in the images corresponding to lower Mo contents in Ringer's solution, which correlates well with the determination of greater $j_{c o r}$ values from the potentiodynamic curves (cf. Table 2). In summary, local electrochemical activity for Ti12Mo and Ti20Mo alloys is smaller in acidic Ringer's solution compared to the neutral environment, whereas the opposite occurs for Ti40Mo. This difference in behaviour may indicate that the passive layer formed on Ti40Mo is more protective, and no passive layer breakdown occurs in the neutral environment as to support positive feedback effects for mediator regeneration. This finding agrees with the proposal of a more compact and protective inner oxide layer formed on Ti40Mo that was made on the basis of the EIS data. Thus, a molybdenum content in TiMo alloys significantly greater than 15 wt.\% leads to a material presenting a more insulating passive film when exposed to Ringer's solution.

\section{Conclusions}

The influence of molybdenum content in the TiMo alloys and of $\mathrm{pH}$ of the simulated physiological solution on the corrosion behaviour of the materials has been characterized using electrochemical and scanning microelectrochemical techniques. These materials show a high corrosion resistance in both neutral and acidic environments, even when subjected to anodic polarizations higher than those experienced in the human body [29]. Therefore, alloys with Mo contents higher than 15 wt.\% should be further investigated for biomedical applications. The $\mathrm{pH}$ value of the Ringer's solution has a minor effect on the corrosion behaviour of TiMo alloys. 
The formation of passive oxide films which are not affected by localized corrosion processes when polarized anodic with respect to their corresponding open circuit potential values is the result of the formation of a two-layer surface film in all cases, in which a thin compact inner oxide layer occurs as evidenced by electrochemical impedance spectroscopy.

The EIS analysis has shown that the resistance of passive layer increased with the content of Mo in TiMo alloys. Also, from potentiodynamic polarization results, the values of corrosion and passive current density decrease with increasing Mo contents in the alloys. Consequently, in the TiMo alloys, surface stability increased as Mo content increased. The TiMo alloys did not show tendency to localized corrosion in these two simulated physiological solutions, though they have been tested under greater anodic polarizations and acidities than those observed in the human body until now.

The passive oxide films formed on TiMo alloys exhibit dielectric characteristics towards charge transfer, and they were imaged as insulators by scanning electrochemical microscopy, even when imaged at their corresponding oсp values in the electrolyte. Eventual activation of the surfaces requires the reduction of the passive surface films under cathodic polarization.

Greater corrosion resistance of Ti40Mo alloy than surgical alloy F 2066 (Ti-15 wt.\% Mo) during exposure to artificial physiological solution was found, even in acidic environment. This behaviour arises from the formation of a more compact inner oxide layer at the metal-oxide interface for this alloy. Therefore, Ti40Mo is regarded a very promising material for the manufacture of implant devices.

\section{Acknowledgments}

The authors are grateful to Prof. Thierry Gloriant (INSA Rennes, France) for kindly providing the TiMo alloys used in this work. This work was supported by the Romanian National Authority for Scientific Research, CNCS-UEFISCDI (project number PN-II-ID-PCE-2011-3-0218), and by the Spanish Ministry of Economy and Competitiveness (MINECO, Madrid) and the European Regional Development Fund under grant No. CTQ2012-36787. A Research Training Grant awarded to J.I. by the MINECO (Programa de Formación de Personal Investigador) is gratefully acknowledged.

\section{References}


[1] H.M. Grandin, S. Berner, M. Dard, A review of titanium zirconium (TiZr) alloys for use in endosseous dental implants, Materials 5 (2012) 1348-1360.

[2] M. Niinomi, M. Nakai, J. Hieda, Development of new metallic alloys for biomedical applications, Acta Biomater. 8 (2012) 3888-3903.

[3] A. Biesiekierski, J. Wang, M.A.H. Gepreel, C. Wen, A new look at biomedical Ti-based shape memory alloys, Acta Biomater. 8 (2012) 1661-1669.

[4] M. Atapour, A.L. Pilchak, G.S. Frankel, J.C. Williams, Corrosion behavior of $\beta$ titanium alloys for biomedical applications, Mater. Sci. Eng. C 31 (2011) 885-891.

[5] M. Aziz-Kerrzo, K.G. Conroy, A.M. Fenelon, S.T. Farrell, C.B. Breslin, Electrochemical studies on the stability and corrosion resistance of titanium-based implant materials, Biomaterials 22 (2001) 1531-1539.

[6] M. Geetha, A.K. Singh, R. Asokamani, A.K. Gogia, Ti based biomaterials, the ultimate choice for orthopaedic implants - A review, Prog. Mater. Sci. 54 (2009) 397-425.

[7] S. Ichinose, T. Muneta, I. Sekiya, S. Itoh, H. Aoki, M. Tagami, The study of metal ion release and cytotoxicity in Co-Cr-Mo and Ti-Al-V alloy in total knee prosthesis, J. Mater. Sci. 14 (2003) 7986.

[8] A. Sarmiento-González, J.M. Marchante-Gayón, J.M. Tejerina-Lobo, J. Paz-Jiménez, A. SanzMedel, High resolution ICP-MS determination of Ti, V, Cr, Co, Ni, and Mo in human blood and urine of patients implanted with a hip or knee prosthesis, Anal. Bioanal. Chem. 391 (2008) 25832589.

[9] Y. Nuevo-Ordóñez, M. Montes-Bayón, E. Blanco-González, J. Paz-Aparicio, J.D. Raimundez, J.M. Tejerina, M.A. Peña, A. Sanz-Medel, Titanium release in serum of patients with different bone fixation implants and its interaction with serum biomolecules at physiological levels, Anal. Bioanal. Chem. 401 (2011) 2747-2754.

[10] O. Addison, A.J. Davenport, R.J. Newport, S. Kalra, J.W.F. Mosselmans, D. Proops, R.A. Martin, Do "passive" medical titanium surfaces deteriorate in service in the absence of wear?, J. Royal Soc. Interface 9 (2012) 3161-3164.

[11] R.M. Souto, G.T. Burstein, A preliminary investigation into the microscopic depassivation of passive titanium implant materials in vitro, J. Mater. Sci. Mater. Med. 7 (1996) 337-343.

[12] G.T. Burstein, C. Liu, R.M. Souto, The effect of temperature on the nucleation of corrosion pits on titanium in Ringer's physiological solution, Biomaterials 26 (2005) 245-256. 
[13] M. Niinomi, Mechanical biocompatibilities of titanium alloys for biomedical applications, J. Mech. Behav. Biomed. Mater. 1 (2008) 30-42.

[14] X. Zhao, M. Niinomi, M. Nakai, J. Hieda, Beta type Ti-Mo alloys with changeable Young's modulus for spinal fixation applications, Acta Biomater. 8 (2012) 1990-1997.

[15] T. Zhou, M. Aindow, S.P. Alpay, M.J. Blackburn, M.H. Wu, Pseudo-elastic deformation behavior in a Ti/Mo-based alloy, Scripta Mater. 50 (2004) 343-348.

[16] L.C. Zhang, T. Zhou, M. Aindow, S.P. Alpay, M.J. Blackburn, Nucleation of stress induced martensites in a Ti/Mo based alloy, J. Mater. Sci. 40 (2005) 2833-2836.

[17] L. De Rosa, C.R. Tomachuk, J. Springer, D.B. Mitton, S. Saiello, F. Bellucci, The wet corrosion of molybdenum thin film -. Part I: Behavior at $25^{\circ} \mathrm{C}$, Mater. Corros. 55 (2004) 602-609.

[18] C.R. Tomachuk, L. De Rosa, J. Springer, D.B. Mitton, S. Saiello, F. Bellucci, The wet corrosion of molybdenum thin film - Part II: Behavior at $85^{\circ} \mathrm{C}$, Mater. Corros. 55 (2004) 665-670.

[19] K.V. Rajagopalan, Molybdenum: An essential trace element in human nutrition, Ann. Rev. Nutr. 8 (1988) 401-427.

[20] S. Kumar, T.S.N. Sankara Narayanan, Corrosion behaviour of Ti-15Mo alloy for dental implant applications, Am. J. Dent. 36 (2008) 500-507.

[21] M.C.R. Alvez Rezende, A.P. Rosifini Alvez, E.N. Codaro, C.A. Matsumoto Dutra, Effect of commercial mouthwashes on the corrosion resistance of Ti-10Mo experimental alloy, J. Mater. Sci. Mater. Med. 18 (2007) 149-154.

[22] N.T.C. Oliveira, A.C. Gustaldi, Electrochemical behavior of Ti-Mo alloys applied as biomaterial, Corros. Sci. 50 (2008) 938-945.

[23] N.T.C. Oliveira, A.C. Gustaldi, Electrochemical stability and corrosion resistance of Ti-Mo alloys for biomedical applications, Acta Biomater. 51 (2009) 399-405.

[24] ASTM F 2066, Standard specification for wrought titanium-15 molybdenum alloy for surgical implant applications (UNS R58150), ASTM International, West Conshohocken, PA, 2011.

[25] D. Mareci, R. Chelariu, I. Dan, D.M. Gordin, T. Gloriant, Corrosion behaviour of $\beta$-Ti20Mo alloy in artificial saliva, J. Mater. Sci. Mater. Med. 21 (2010) 2907-2913.

[26] D.M. Gordin, E. Delvat, R. Chelariu, G. Ungureanu, M. Besse, M. Laille, T. Gloriant, Characterization of Ti-Ta alloys synthesized by cold crucible levitation melting, Adv. Eng. Mater. 10 (2008) 714-719. 
[27] D. Mareci, G. Ciurescu, R. Chelariu, I. Cretescu, D. Sutiman, In vitro corrosion study by electrochemical and surface analysis techniques of a Ti50Ta alloy for dental applications, Environ. Eng. Manag. J. 9 (2010) 81-87.

[28] P. Ducheyne, G. Willems, M. Martens, J. Helsen, In vivo metal-ion release from porous titaniumfiber material, J. Biomed. Mater. Res. 18 (1984) 293-308.

[29] T.P. Hoar, D.C. Mears, Corrosion-resistant alloys in chloride solutions: materials for surgical implants, Proc. Royal Soc. London A 294 (1966) 486-510.

[30] B. Yeum, Electrochemical impedance spectroscopy: Data analysis software; Echem Software, Ann Arbor, 2001.

[31] G. Ciurescu, J. Izquierdo, J. J. Santana, D. Mareci, D. Sutiman, S. González, R.M. Souto, Characterization of the localized surface chemical activity of Ti-Mo and Ti-Ta alloys for biomedical applications using scanning electrochemical microscopy, Int. J. Electrochem. Sci. 7 (2012) 7404-7424.

[32] W.F. Ho, C.P. Hu, J.H.C. Lin, Structure and properties of cast binary Ti-Mo alloys, Biomaterials 20 (1999) 2115-2122.

[33] M. Geetha, U.M. Kamachi, A.K. Gogia, R. Asokamani, R. Baldev, Influence of microstructure and alloying elements on corrosion behaviour of Ti-13Nb-13Zr alloy, Corros. Sci. 46 (2004) 877-892.

[34] D.J. Blackwood, A.W.C. Chua, K.H.W. Seah, R. Trampuran, S.H. Teoh, Corrosion behaviour of porous titanium-graphite composites designed for surgical implants, Corros. Sci. 42 (2003) 481503.

[35] M.H. Wong, F.T. Cheng, H.C. Man, Laser oxidation of NiTi for improving corrosion resistance in Hank’s solution, Mater. Lett. 61 (2007) 3391-3394.

[36] G. Bolat, J. Izquierdo, J.J. Santana, D. Mareci, R.M. Souto, Electrochemical characterization of ZrTi alloys for biomedical applications, Electrochim. Acta 88 (2013) 447-456.

[37] D.D. Macdonald, G. R. Engelhardt, The point defect model for bi-layer passive films, ECS Transactions 28 (14) (2010) 123-144.

[38] J. Pan, D. Thierry, C. Leygraf, Electrochemical impedance spectroscopy study of the passive oxide film on titanium for implant application, Electrochim. Acta 41 (1996) 1143-1153.

[39] J.E.G. Gonzalez, J.C. Mirza Rosca, Study of the corrosion behavior of titanium and some of its alloys for biomedical and dental implant applications, J. Electroanal. Chem. 471 (1999) 109-115. 
[40] M.C. García Alonso, L. Saldaña, G. Valles, In vitro corrosion behaviour and osteoblast response of thermally-oxidised Ti-6Al-4V alloy, Biomaterials 24 (2003) 19-26.

[41] S.L. Assis, S. Wolynec, I. Costa, Corrosion characterization of titanium alloys by electrochemical techniques, Electrochim. Acta 51 (2006) 1815-1819.

[42] V. Barranco, M.L. Escudero, M.C. García-Alonso, 3D, chemical and electrochemical characterization of blasted TI6Al4V surfaces: Its influence on the corrosion behaviour, Electrochim. Acta 52 (2007) 4374-4384.

[43] I.C. Lavos-Valereto, S. Wolynec, I. Ramires, A.C. Guastaldi, I. Costa, Electrochemical impedance spectroscopy characterization of passive film formed on implant Ti6Al7Nb alloy in Hank's solution, J. Mater. Sci. Mater. Med. 15 (2004) 55-59.

[44] I. Milosev, T. Kosec, H.H. Strehblow, XPS and EIS study of the passive film formed on orthopaedic Ti-6Al-7Nb alloy in Hank’s physiological solution, Electrochim. Acta 53 (2008) 3547-3558.

[45] V. Raman, S. Nagarajan, N. Rajendran, Electrochemical impedance spectroscopic characterisation of passive film formed over $\beta$ Ti-29Nb-13Ta-4.6Zr alloy, Electrochem. Commun. 8 (2006) 13091314.

[46] A. Cremasco, W.R. Osorio, C.M.A. Freire, A. Garcia, R. Caram, Electrochemical corrosion behavior of a Ti-35Nb alloy for medical prostheses, Electrochim. Acta 53 (2008) 4867-4874.

[47] F. Rosalbino, D. Maccio, G. Scavino, A. Saccone, In vitro corrosion behaviour of Ti-Nb-Sn shape memory alloys in Ringer’s physiological solution J. Mater. Sci. Mater. Med. 23 (2012) 865-871.

[48] B.I. Wang, Y.F. Zheng, I.C. Zhao, Effects of Hf content and immersion time on electrochemical behavior of biomedical Ti-22Nb-xHf alloys in 0.9\% NaCl solution, Mater. Corros. 60 (2009) 330335.

[49] N. Figueira, T.M. Silva, M.J. Carmezim, J.C.S. Fernandes, Corrosion behaviour of NiTi alloy, Electrochim. Acta 54 (2009) 921-926.

[50] G. Bolat, J. Izquierdo, D. Mareci, D. Sutiman, R.M. Souto, Electrochemical characterization of ZrTi alloys for biomedical applications. Part 2. The effect of thermal oxidation, Electrochim. Acta, 106 (2013) 432-439.

[51] J.R. Macdonald, Note on the parameterization of the constant-phase admittance element, Solid State Ionics 13 (1984) 147-149. 
[52] L.J. Berberich, M.E. Bell, The dielectric properties of the rutile form of $\mathrm{TiO}_{2}$, J. Appl. Phys. 11 (1940) 681-692.

[53] R.A. Parker, Static dielectric constant of rutile ( $\left.\mathrm{TiO}_{2}\right)$, Phys. Rev. 124 (1961) 1719-1722.

[54] G.S. Nadkarni, J.G. Simmons, Electrical properties of evaporated molybdenum oxide films, J. Appl. Phys. 41 (1970) 545-551.

[55] S.E. Pust, D. Scharnweber, S. Baunack, G. Wittstock, Electron transfer kinetics at oxide films on metallic biomaterials. Scanning electrochemical microscopy studies of Ti6Al4V, J. Electrochem. Soc. 154 (2007) C508-C514.

[56] R. Zhu, Z. Qin, J.J. Noël, D.W. Shoesmith, Z. Ding, Analyzing the influence of alloying elements and impurities on the localized reactivity of titanium grade-7 by scanning electrochemical microscopy, Anal. Chem. 80 (2008) 1437-1447.

Table 1. Open circuit potential values attained by the TiMo alloys immersed in the artificial physiological solutions at room temperature after 1 hour.

\begin{tabular}{ccc}
\hline \multirow{2}{*}{ Alloy } & \multicolumn{2}{c}{$E_{\text {ocp }} / \mathrm{V}$ vs. SCE } \\
& Ringer's solution & Acidic Ringer's solution \\
& $-0.221 \pm 0.027$ & $-0.305 \pm 0.053$ \\
Ti12Mo & $-0.148 \pm 0.024$ & $-0.281 \pm 0.061$ \\
\hline Ti20Mo & $-0.104 \pm 0.019$ & $-0.252 \pm 0.050$ \\
\hline Ti40Mo & \\
\hline
\end{tabular}


Table 2. Electrochemical parameters determined from the potentiodynamic polarization curves measured for the TiMo alloys in aerated the artificial physiological solutions at room temperature.

\begin{tabular}{cccc}
\hline Alloy & $E_{\text {cor }} / \mathrm{V}$ vs. SCE & $j_{\text {cor }} / \mathrm{nA} \mathrm{cm}^{-2}$ & $j_{\text {pas }}{ }^{*} / \mu \mathrm{A} \mathrm{cm}^{-2}$ \\
\hline \multicolumn{4}{c}{ Ringer's solution $(\mathbf{p H}=\mathbf{6 . 9})$} \\
Ti12Mo & $-0.365 \pm 0.071$ & $190 \pm 16.7$ & $0.600 \pm 0.148$ \\
Ti20Mo & $-0.260 \pm 0.064$ & $130 \pm 12.5$ & $0.500 \pm 0.201$ \\
Ti40Mo & $-0.185 \pm 0.050$ & $80 \pm 16.5$ & $0.300 \pm 0.090$ \\
& Acidic Ringer's solution (pH = 3.1) \\
Ti12Mo & $-0.435 \pm 0.060$ & $250 \pm 24.0$ & $2.1 \pm 0.180$ \\
Ti20Mo & $-0.404 \pm 0.092$ & $160 \pm 8.2$ & $1.2 \pm 0.130$ \\
\hline Ti40Mo & $-0.377 \pm 0.076$ & $110 \pm 8.5$ & $0.9 \pm 0.127$ \\
\hline
\end{tabular}

Table 3. Parameters of the equivalent circuit for TiMo alloys in Ringer's solution and acidic Ringer's solution at room temperature. AC polarization was applied around their corresponding open circuit potential values in the electrolytes.

\begin{tabular}{|c|c|c|c|c|c|c|}
\hline Alloy & $\begin{array}{l}10^{5} Q_{1} / \\
S^{-2} \mathrm{~cm}^{-2}\end{array}$ & $n_{1}$ & $\begin{array}{c}\mathrm{R}_{1} / \\
\mathrm{k} \Omega \mathrm{cm}^{2}\end{array}$ & $\begin{array}{l}10^{6} Q_{2} / \\
\mathrm{S} \mathrm{cm}^{-2} \mathrm{~s}^{n}\end{array}$ & $n_{2}$ & $\begin{array}{c}R_{2} / \\
\mathrm{M} \Omega \mathrm{cm}^{2}\end{array}$ \\
\hline \multicolumn{7}{|c|}{ Ringer's solution $(\mathrm{pH}=6.9)$} \\
\hline Ti12Mo & 2.1 & 0.86 & 26 & 8.8 & 0.83 & 2.9 \\
\hline Ti20Mo & 1.9 & 0.87 & 29 & 7.4 & 0.85 & 4.3 \\
\hline Ti40Mo & 1.9 & 0.87 & 35 & 7.1 & 0.85 & 5.4 \\
\hline \multicolumn{7}{|c|}{ Acidic Ringer's solution $(\mathrm{pH}=3.1$ ) } \\
\hline Ti12Mo & 1.9 & 0.86 & 59 & 9.1 & 0.82 & 2.6 \\
\hline Ti20Mo & 1.6 & 0.87 & 72 & 7.7 & 0.84 & 3.3 \\
\hline Ti40Mo & 1.6 & 0.88 & 85 & 7.3 & 0.84 & 4.8 \\
\hline
\end{tabular}


Table 4. Film thickness estimated from EIS results measured for TiMo alloys in Ringer's solution and acidic Ringer's solution at room temperature. Dielectric constant values of 114 for $\mathrm{TiO}_{2}$ [52,53] and 16 for $\mathrm{MoO}_{3}[54]$ were assumed in the calculation.

\begin{tabular}{|c|c|c|}
\hline Sample & $\begin{array}{l}\text { Capacitance of the } \\
\text { inner oxide layer / } \mu \mathrm{F} \\
\mathrm{cm}^{-2}\end{array}$ & $\begin{array}{c}\text { Film thickness of } \\
\text { the inner oxide } \\
\text { layer / nm }\end{array}$ \\
\hline \multicolumn{3}{|c|}{ Ringer's solution, $E=E_{o c p}$} \\
\hline Ti12Mo & 19.0 & 5.7 \\
\hline Ti20Mo & 17.4 & 6.6 \\
\hline Ti40Mo & 17.9 & 5.4 \\
\hline \multicolumn{3}{|c|}{ Ringer's solution, $E=+0.40 \mathrm{~V}$ vs. SCE } \\
\hline Ti12Mo & 19.4 & 5.4 \\
\hline Ti20Mo & 16.3 & 6.4 \\
\hline Ti40Mo & 16.7 & 5.0 \\
\hline \multicolumn{3}{|c|}{ Acidic Ringer's solution, $E=E_{o c p}$} \\
\hline Ti12Mo & 18.0 & 5.7 \\
\hline Ti20Mo & 17.9 & 6.4 \\
\hline Ti40Mo & 18.2 & 5.2 \\
\hline \multicolumn{3}{|c|}{ Acidic Ringer's solution, $E=+0.40 \mathrm{~V}$ vs. SCE } \\
\hline Ti12Mo & 14.4 & 5.5 \\
\hline Ti20Mo & 13.5 & 5.3 \\
\hline Ti40Mo & 14.2 & 5.0 \\
\hline
\end{tabular}


Table 5. Parameters of the equivalent circuit for TiMo alloys in Ringer's solution and acidic Ringer's solution at room temperature. AC potential signal was applied to the samples polarized at $+0.40 \mathrm{~V}$ vs SCE.

\begin{tabular}{|c|c|c|c|c|c|c|}
\hline Alloy & $\begin{array}{l}10^{5} Q_{1} / \\
\mathrm{S} \mathrm{cm}^{-2} \mathrm{~s}^{n}\end{array}$ & $n_{1}$ & $\begin{array}{c}R_{1} / \\
\mathrm{k} \Omega \mathrm{cm}^{2}\end{array}$ & $\begin{array}{l}10^{6} Q_{2} / \\
\mathrm{S} \mathrm{cm}^{-2} \mathrm{~s}^{n}\end{array}$ & $n_{2}$ & $\begin{array}{c}R_{2} / \\
M \Omega \mathrm{cm}^{2}\end{array}$ \\
\hline \multicolumn{7}{|c|}{ Ringer's solution $(\mathrm{pH}=6.9)$} \\
\hline Ti12Mo & 1.9 & 0.87 & 36 & 8.8 & 0.84 & 3.6 \\
\hline Ti20Mo & 1.8 & 0.88 & 53 & 7.5 & 0.85 & 4.9 \\
\hline Ti40Mo & 1.8 & 0.88 & 61 & 7.1 & 0.85 & 6.2 \\
\hline \multicolumn{7}{|c|}{ Acidic Ringer's solution ( $\mathrm{pH}=3.1$ ) } \\
\hline Ti12Mo & 1.4 & 0.88 & 88 & 9.1 & 0.83 & 3.1 \\
\hline Ti20Mo & 1.3 & 0.89 & 102 & 8.9 & 0.84 & 3.5 \\
\hline Ti40Mo & 1.3 & 0.89 & 154 & 7.2 & 0.84 & 5.2 \\
\hline
\end{tabular}
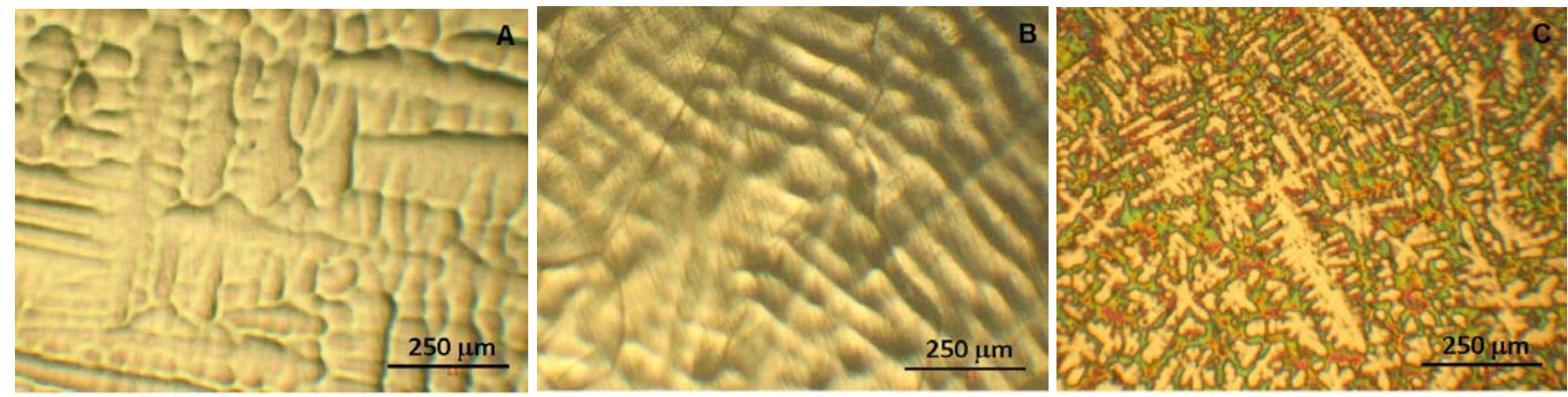

Figure 1.

Optical micrographs of the TiMo alloys: (A) Ti12Mo, (B) Ti20Mo, and (C) Ti40Mo. 

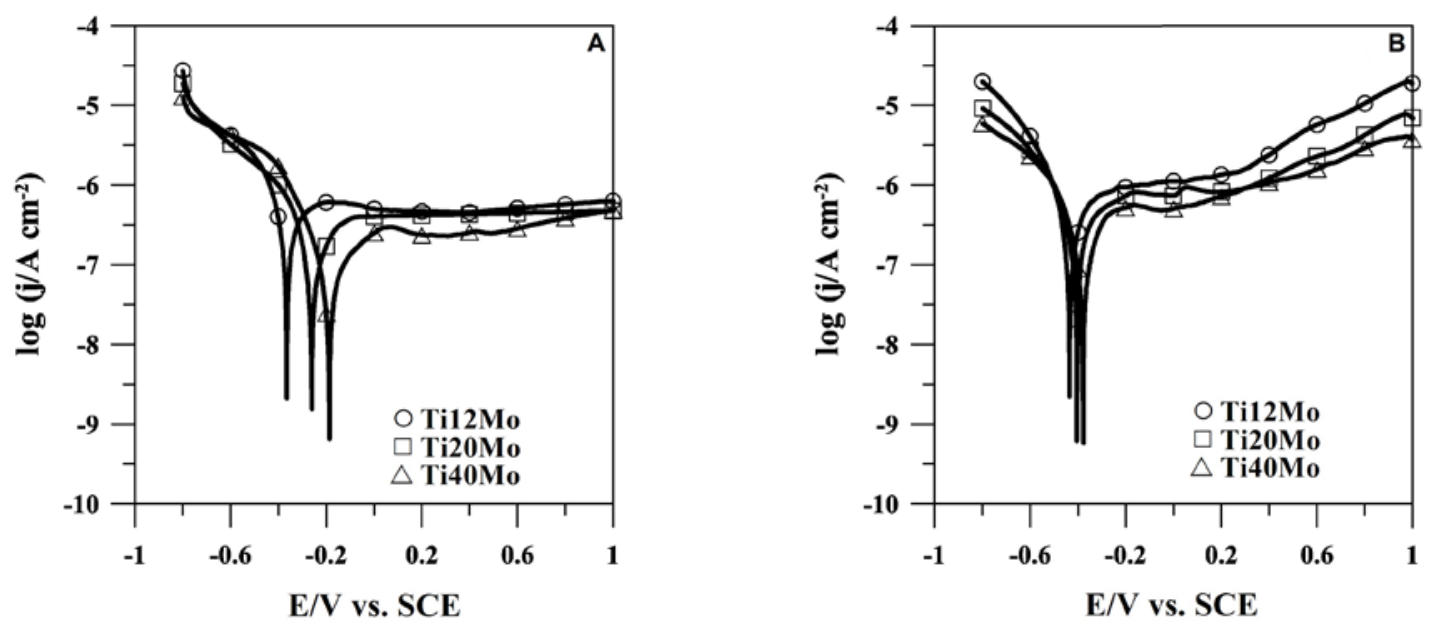

Figure 2.

Potentiodynamic polarization curves of TiMo alloys in (A) Ringer's solution, and (B) acidic Ringer's solution at room temperature. $v=0.5 \mathrm{mV} \mathrm{s}^{-1}$. Curves determined from individual samples.

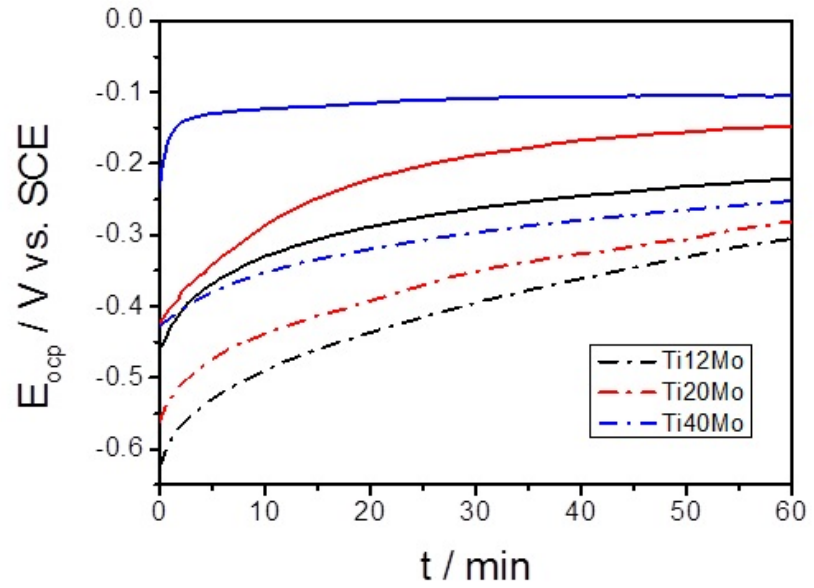

\section{Figure 3.}

Open circuit potential $\left(E_{o c p}\right)$ as a function of time for TiMo alloys in (solid) Ringer's solution, and (dashed) acidic Ringer’s solution at room temperature. Curves determined from individual samples. 

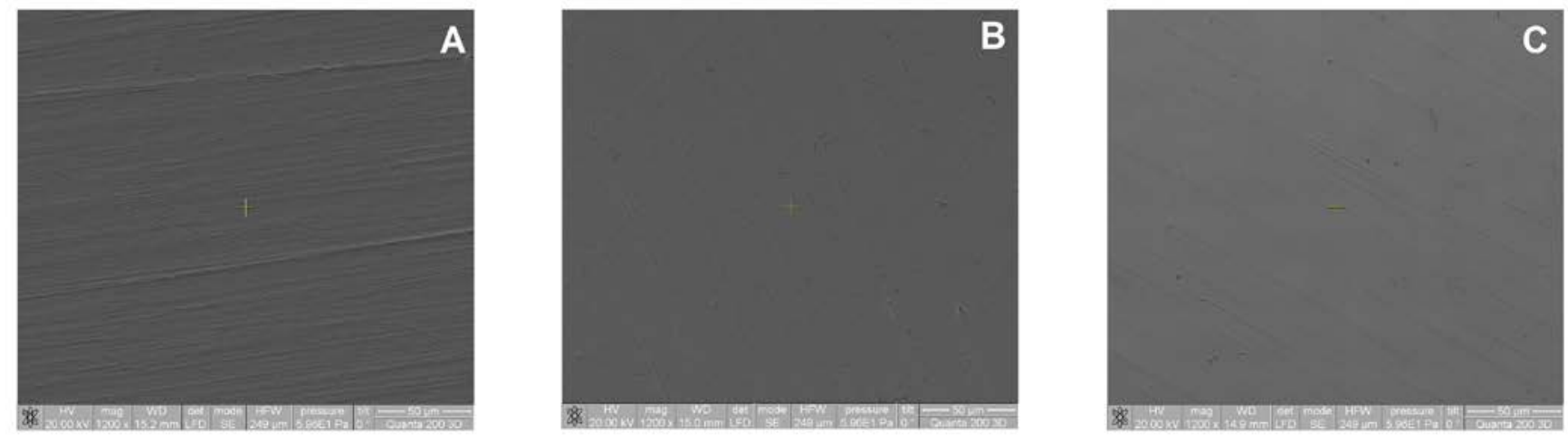

$100 \mu \mathrm{m}$

\section{Figure 4.}

The morphologies of the surfaces of the TiMo alloys retrieved from acidic Ringer's solution after potentiodynamic polarization to +1.00 V vs. SCE. (A) Ti12Mo, (B) Ti20Mo, and (C) Ti40Mo.
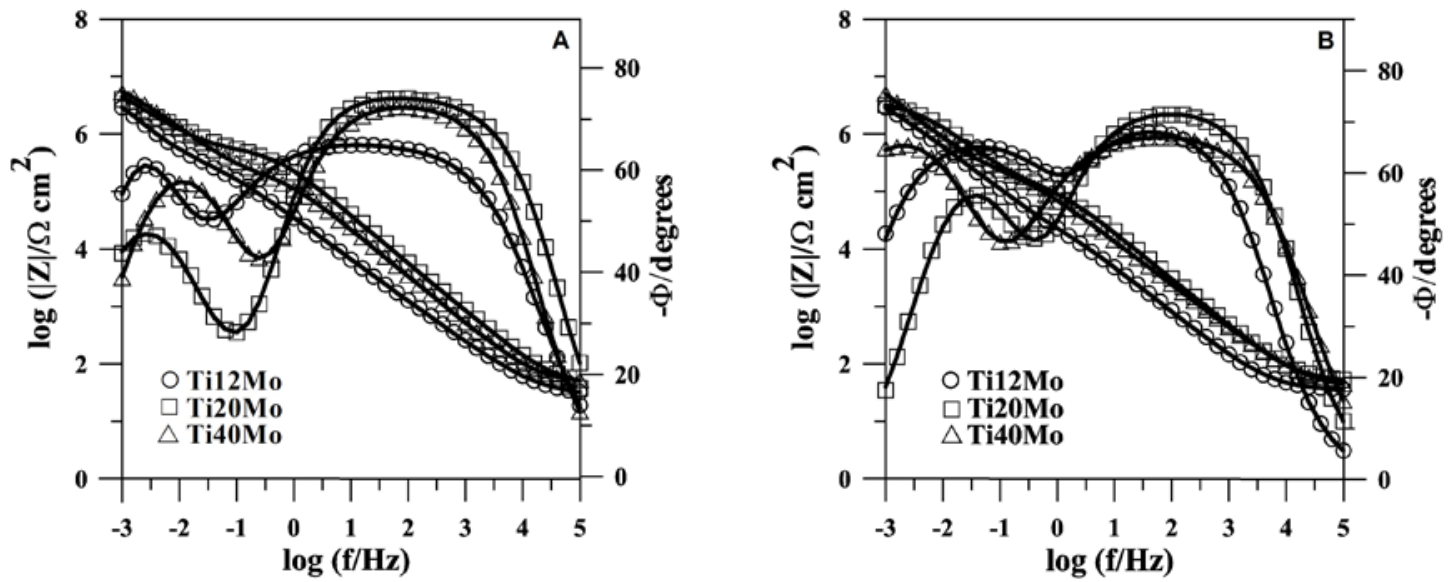

Figure 5.

Measured (discrete points) and fitted (solid lines) impedance spectra for TiMo alloys at their corresponding E Ecp during exposure to: (A) Ringer's solution, and (B) acidic Ringer's solution at room temperature. 


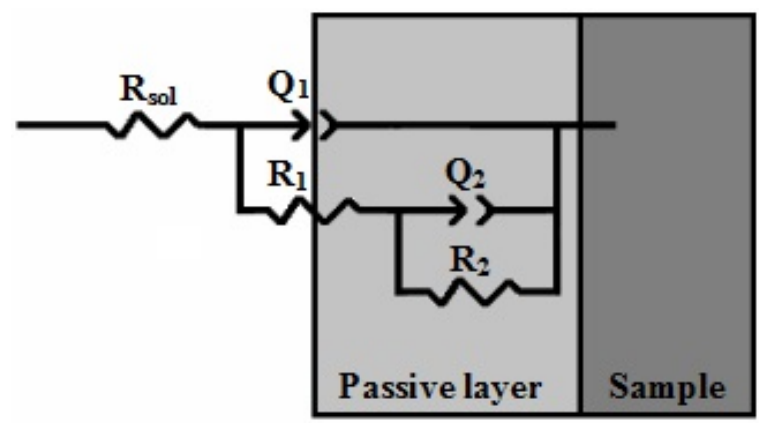

\section{Figure 6.}

Equivalent circuit (EC) used to fit the impedance data.
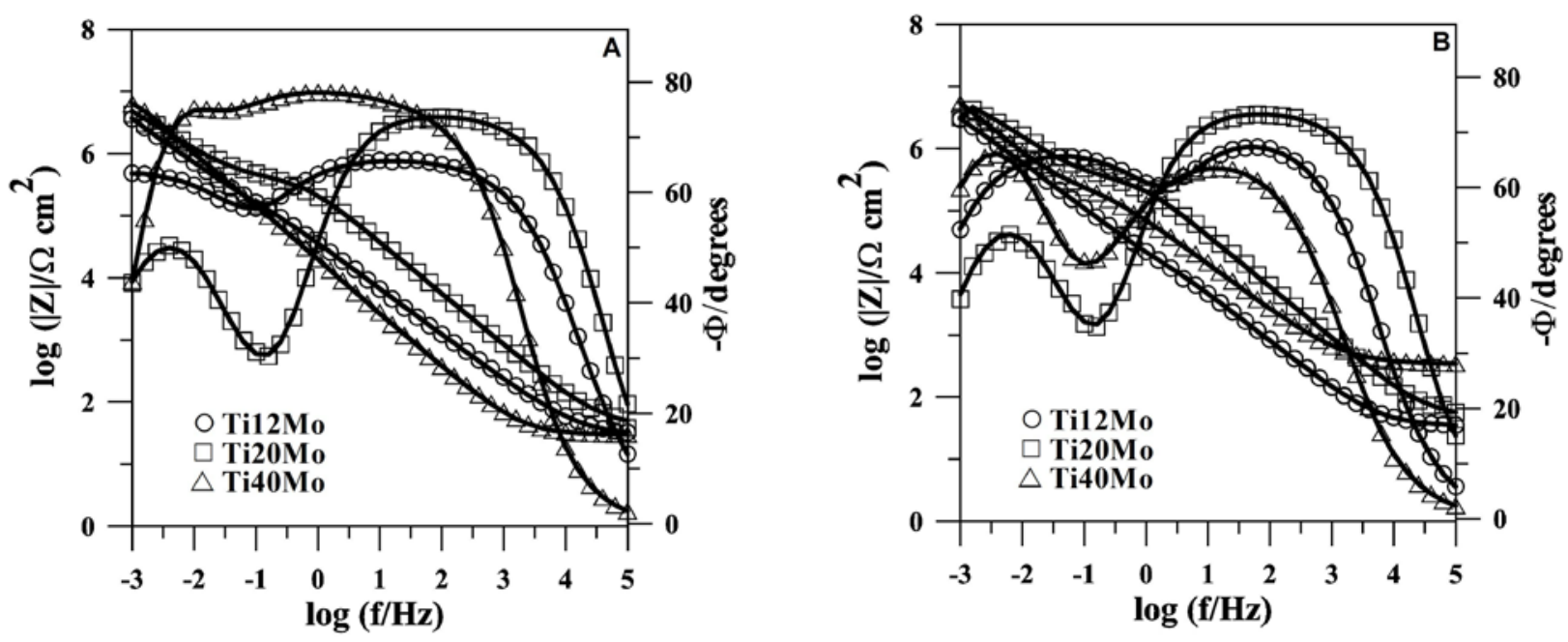

Figure 7.

Measured (discrete points) and fitted (solid lines) impedance spectra for TiMo alloys polarized at +0.40 V vs. SCE during exposure to: (A) Ringer's solution, and (B) acidic Ringer's solution at room temperature. 
Ringer's solution
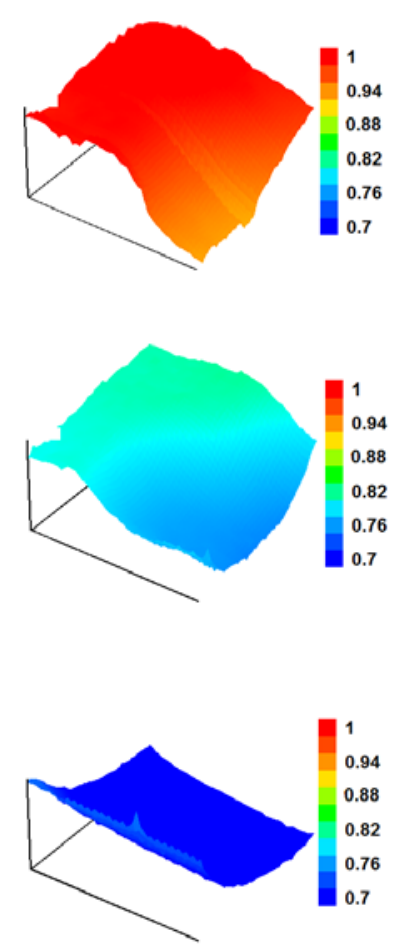

\section{acidic Ringer's solution}

(A)

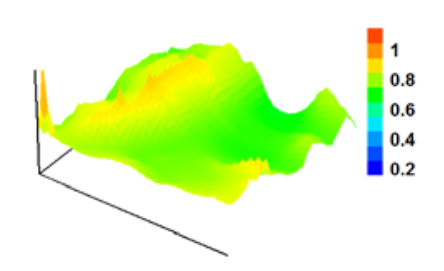

(B)

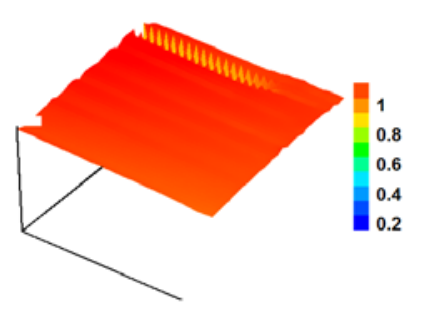

(C)

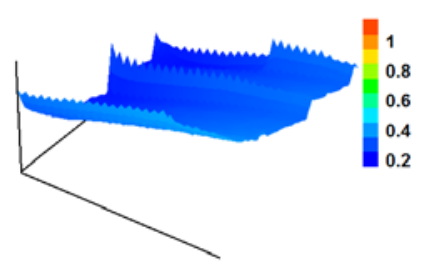

Figure 8.

Images generated by SECM of Ti12Mo alloy during exposure to (left) Ringer's solution, and (right) acidic Ringer's solution at room temperature. Electric condition of the samples: (A) unbiased, and (B-C) under polarization. Applied potential values: (B) -0.54 , and (C) +0.16 V vs. SCE. Tip-substrate distance: $10 \mu \mathrm{m}$. Tip potential: $+0.46 \mathrm{~V}$ vs. SCE. Scan rate: $30 \mu \mathrm{m} \mathrm{s}^{-1}$. The figures represent an area of $250 \mu \mathrm{m} \times 250 \mu \mathrm{m}$ in $x$ and $y$ directions. 
Ringer's solution
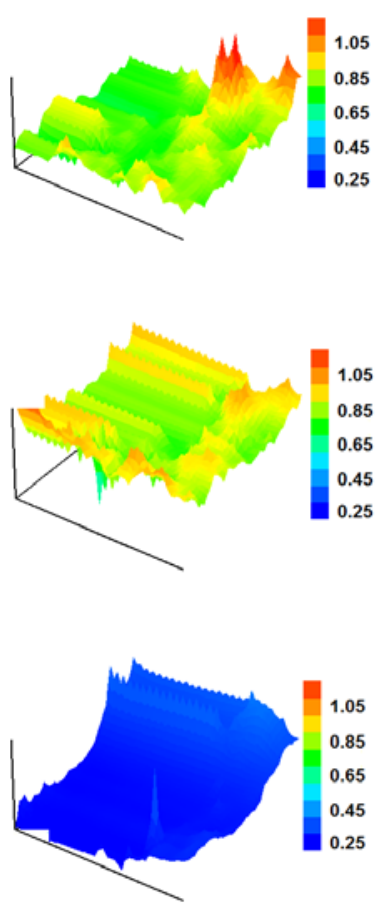

\section{acidic Ringer's solution}

(A)

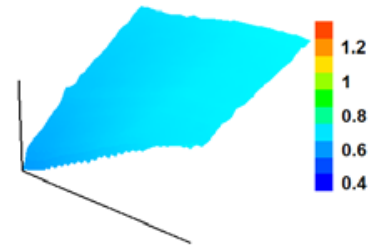

(B)

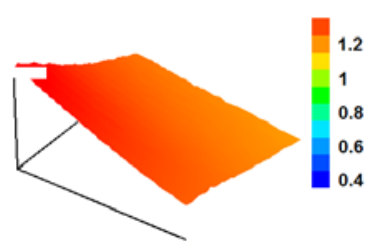

(C)

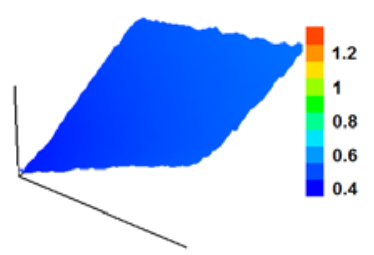

Figure 9.

Images generated by SECM of Ti20Mo alloy during exposure to (left) Ringer's solution, and (right) acidic Ringer's solution at room temperature. Electric condition of the samples: (A) unbiased, and (B-C) under polarization. Applied potential values: (B) -0.54 , and (C) +0.16 V vs. SCE. Tip-substrate distance: $10 \mu \mathrm{m}$. Tip potential: $+0.46 \mathrm{~V}$ vs. SCE Scan rate: $30 \mu \mathrm{m} \mathrm{s}^{-1}$. The figures represent an area of $250 \mu \mathrm{m} \times 250 \mu \mathrm{m}$ in $x$ and $y$ directions. 
Ringer's solution
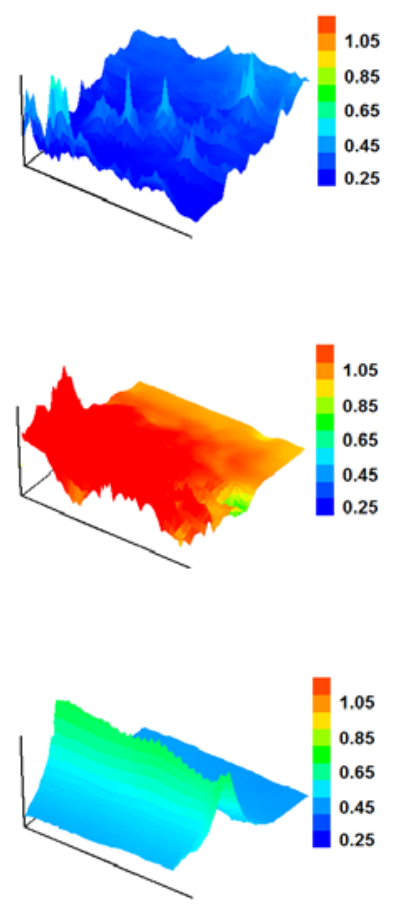

\section{acidic Ringer's solution}

(A)

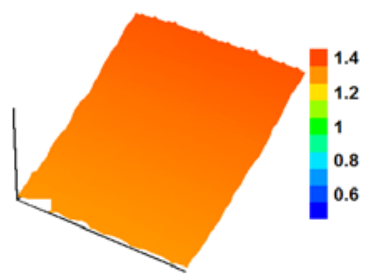

(B)

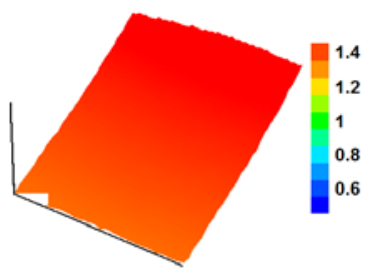

(C)

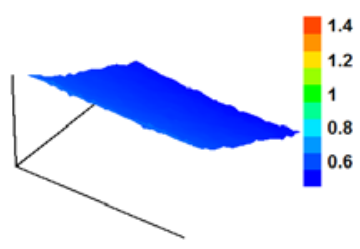

\section{Figure 10.}

Images generated by SECM of Ti40Mo alloy during exposure to (left) Ringer's solution, and (right) acidic Ringer's solution at room temperature. Electric condition of the samples: (A) unbiased, and (B-C) under polarization. Applied potential values: (B) -0.54 , and (C) $+0.16 \mathrm{~V}$ vs. SCE. Tip-substrate distance: $10 \mu \mathrm{m}$. Tip potential: $+0.46 \mathrm{~V}$ vs. SCE. Scan rate: $30 \mu \mathrm{m} \mathrm{s}^{-1}$. The figures represent an area of $250 \mu \mathrm{m} \times 250 \mu \mathrm{m}$ in $x$ and $y$ directions. 